not suggest that our approach is necessarily always the best. Table III summarises the strategies recommended for different circumstances. The approach taken by Cao et $a l^{11}$ is likely to be more suitable in areas of South East Asia with very high

TABLE III-Recommended strategies of screening for $\beta$-thalassaemias in different areas

\begin{tabular}{|c|c|c|c|c|c|}
\hline $\begin{array}{l}\text { Percentage of } \\
\text { thalassaemia } \\
\text { in area }\end{array}$ & $\begin{array}{c}\text { Size of } \\
\text { population }\end{array}$ & $\begin{array}{l}\text { Availability } \\
\text { of resources }\end{array}$ & Procedure & $\begin{array}{l}\text { Percentage } \\
\text { undetected } \\
\text { thalassaemics }\end{array}$ & $\begin{array}{l}\text { Mean cost } \\
\text { per sample } \\
\quad(£)\end{array}$ \\
\hline 10 & $>M$ & Poor & $\begin{array}{l}\text { Step } 1 \text { for } \\
\text { whole sample } \\
\text { and step } 2 \\
\text { on } 15 \% \text { of } \\
\text { whole sample }\end{array}$ & $0 \cdot 34$ & $1 \cdot 1$ \\
\hline $10-20$ & $1 \mathrm{M}$ & Reasonable & $\begin{array}{l}\text { Steps } 1 \text { and } 2 \\
\text { on whole } \\
\text { sample }\end{array}$ & 0 & 3.5 \\
\hline $\begin{array}{l}\geqslant 10 \\
\text { abnormal } \\
\text { haemoglobins }\end{array}$ & $1 \mathrm{M}$ & Poor & $\begin{array}{l}\text { Electropho- } \\
\text { resis on } \\
\text { whole sample }\end{array}$ & 0 & $1 \cdot 8$ \\
\hline
\end{tabular}

incidence of $\alpha$-thalassaemia and $\beta$-thalassaemia, of haemoglobin $E$, and of iron deficiency anaemias. For areas with intermediate incidence, however, such as most of Italy and probably most of southern Europe, the approach we have described would seem to provide a high level of reliability with a low cost.

We thank Professors Lucio Luzzatto and Guido Modiano for their helpful criticism.

\section{References}

' Silvestroni E, Bianco I. Screening of microcythaemia in Italy: analysis of data collected in the past 30 years. Am f Hum Genet 1975;27:198-212.

2 Silvestroni E, Bianco I. Il metodo di Simmel per lo studio delle resistenze globulari. Policlinico, Sezione Pratica 1945;51:153-5.

${ }^{3}$ Betke K, Marti HR, Schlich L. Estimation of small percentage of foetal hemoglobin. Nature 1959;184:1877-8.

${ }^{4}$ Bianco I, Graziani B, Salvini P, Mastromonaco I, Silvestroni E. Fréquence et caractères de l'alpha microcitémie dans les populations de la Sardaigne septentrionale. Nouv Rev Fr Hematol 1972;12:191-200.

${ }^{5}$ Bianco I, Lerone M, Valente $M$, Carboni $C$. Confronto fra due diverse strategie di screening delle microcitemie. In: Proceedings of the sixth international congress on "La prevenzione delle malattie microcitemiche," Rome 1980. Torino: Minerva Medica, 1981:199-200.

${ }^{6}$ Graziani B, Bianco I, Carboni C, et al. Tecniche e strategie di screening di massa delle microcitemie. In: Proceedings of the sixth international congress on "La prevenzione delle malattie microcitemiche," Rome 1980. Torino: Minerva Medica, $1981: 185-9$

${ }^{7}$ Silvestroni E, Bianco I. Sull'esistenza nella popolazione italiana di soggetti non microcitemici portatori di un'elevata quota di emoglobina lenta $\left(\mathrm{Hb} \mathrm{A}_{2}\right)$ e sui loro rapporti con i malati di anemia microcitica. Policlinico, Sezione Pratica 1957;64:1868-72.

${ }^{8}$ Pearson HA, McFedran P, O’Brien RT, Aspness GT, McIntosh S, Guiliotis DK. Comprehensive testing for thalassaemia trait. Ann NY Acad Sci 1974;232:135-44.

${ }^{9}$ Shine I, Lal S. A strategy to detect $\beta$-thalassaemia minor. Lancet 1977 ;i : $692-4$.

10 Kattamis C, Efremov G, Pootrakul S. Effectiveness of one tube osmotic fragility screening in detecting $\beta$-thalassaemia trait. 7 Med Genet 1981;18:266-70.

" Cao A, Furbetta $M$, Galanello $R$, et al. Prevention of homozygous 3 -thalassemia by carriers screening and prenatal diagnosis in Sardinia. Am f Hum Genet 1981 ;33:592-605.

(Accepted 19 fanuary 1983)

\title{
Influence of Doppler ultrasound on fetal activity
}

\author{
A J MURRILLS, P BARRINGTON, P D HARRIS, T WHEELER
}

\begin{abstract}
A randomised and double blind study of 100 subjects and 50 controls was performed to confirm or refute a report from Cardiff in 1975 that continuous Doppler ultrasound, as used in fetal heart rate monitoring, increases fetal movement by over $90 \%$. The results showed such an effect to be most unlikely (power $>0.99$ ). A total of 150 pregnant mothers recorded fetal movements for 30 minutes while connected to a specially modified cardiotocograph, the ultrasound being switched on at random for either the first or second 15 minutes in 100 of the patients. The mean difference in 15 minute movement count, with and without ultrasound, among the 100 patients was 0.2 of a movement (SD 12.7; p >0.6
\end{abstract}

Wessex Regional Department of Medical Physics, Southampton General Hospital, Southampton SO9 4XY

A J MURRILLS, MSC, principal physicist

University of Southampton, Southampton SO9 5NH

P BARRINGTON, medical student

P D HARRIS, medical student

Princess Anne Hospital, Southampton

$T$ WHEELER, DM, MRCOG, senior lecturer in human reproduction and obstetrics

Correspondence to: $\mathrm{Mr}$ A J Murrills, Wessex Regional Department of Medical Physics, Level D, Centre Block, Southampton General Hospital, Southampton SO9 $4 \mathrm{XY}$. by two tailed Wilcoxon matched pairs signed ranks test). The control group showed a mean difference of 2.6 movements (SD 12.1; $p>0 \cdot 2$ ).

Results of a pilot study suggested that the observations in the earlier report may have been influenced by mechanisms unrelated to ultrasound.

\section{Introduction}

In 1975 David et al reported that exposure of the fetus to Doppler ultrasound caused an increase in fetal activity of over $90 \% .^{1}$ Four years later, however, two other studies were published, ${ }^{23}$ and neither of these was confirmatory. Unfortunately none of these studies was performed double blind and each included only a small number of subjects; there were also appreciable differences between them in experimental design.

Because of the important implications of the results of David et al we decided that a large, randomised, controlled, and double blind experiment should be carried out, but whose design should deliberately be kept sufficiently similar to that of David et al to permit a meaningful comparison of results. In order to optimise the design of the main study and provide preliminary information on fetal movement we also mounted a pilot study.

\section{Pilot study}

Fetal movements felt by 50 mothers or seen by an observer watching the abdomen were recorded separately on a two channel chart recorder using hand held push buttons. No ultrasound equipment was 
used during the recordings, which lasted for 30 minutes. All the patients were between 28 and 42 weeks of gestation and were selected at random from a population resting in hospital with various complications of pregnancy. Certain patients were not studied, however, including those with ruptured membranes, hydramnios or twins, and those in early labour. Patients taking uterine relaxants or drugs which could influence the central nervous system were also excluded, as were those in whom fetal hiccups occurred during the recording. The patient lay in a lateral or semirecumbent position to avoid supine hypotension, the blood pressure being checked before and after the recording. Smoking habits and time of last cigarette, maternal activity immediately before the recording, time of recording, and times of last meal and drink (tea or coffee) were also noted.

There was a wide range in the recorded fetal movement counts, with maternal observations varying from zero to 127 per half hour. The mean half hour count was $29 \cdot 3$ (SD 26.2), the distribution being positively skewed and approximately exponential in shape. Observer counts were at a lower level, on average, ranging from zero to 95 per half hour (mean 21.7; SD 25.2), the distribution having a similar shape to that for the maternal counts. Although the difference between the mother and observer was statistically highly significant ( $p<0.0001$, two tailed Wilcoxon matched pairs signed ranks test), there was good correlation between maternal and observer measurements (Spearman's rank correlation coefficient $\simeq 0.8, p<0.001$, for 15 minute or 30 minute totals and for differences between first and second 15 minute periods). Other workers have also shown maternal appreciation of fetal movement to compare reasonably well with several non-ultrasound techniques ${ }^{4-6}$ and, in the case of major fetal movements, also with real time ultrasound scanning " (which, of course, could not be used in this study). The mother alone therefore recorded fetal movements in our main study, this also being the technique used by David et al. ${ }^{1}$

When the recordings in the pilot study were divided into two equal 15 minute epochs and the differences in the fetal movement counts between the two epochs were examined, a significantly higher incidence of fetal movement was found in the second 15 minute period $(p<0.01$, two tailed Wilcoxon matched pairs signed ranks test applied either to mothers' or to observers' figures). In an attempt to discover the cause of this effect the patients were categorised according to the following factors: time since last meal, time since last cigarette (if any), degree of maternal activity before the recording, and change in blood pressure during the recording. Only smoking appeared to affect the results, though not in a way which could explain the above finding. There was a trend towards lower counts and smaller increases over the half hour in those patients who had smoked recently (less than one and a half hours beforehand), with some suggestion that the more recent the smoking the lower the counts and increases. There were too few patients, however, to permit convincing demonstration of statistical significance. None the less, because our observations were consistent with those of Thaler et $a l,{ }^{9}$ who had shown maternally appreciated fetal movements to be significantly reduced after two cigarettes, we decided that patients in the main study should not smoke for at least one and a half hours before their recording.

As recent smoking was not, however, the cause of the increased fetal movement recorded in the second 15 minute epoch of the pilot study (this becoming even more pronounced when such patients were eliminated from the results) the effect remained unexplained and therefore had to be taken into account in the design of the main study by including a control group. This took the form of a set of patients to whom no ultrasound was applied. We also considered including a further group to whom ultrasound would be applied continuously, as this would have enabled possible interaction effects between time and ultrasound to be investigated more closely. We did not do this, however, because either more patients would have been needed or the power of the study to investigate the effect of prime importance (namely, whether or not ultrasound had any effect at all) would have been reduced.

The data from the pilot study also enabled an estimate to be made of the number of patients required in the main study to give a high probability of detecting as statistically significant any effect due to ultrasound of the magnitude suggested by David et al. ${ }^{1}$ Using Altman's nomogram, ${ }^{10}$ modified for paired data, we estimated that at the count levels reported by patients in our pilot study a sample size of 50 would give a very high probability $(0.99)$ of showing the $90 \%$ increase in fetal movement claimed by David et al as being significant at the $1 \%$ level. This size of sample would still be expected to give a power of some $90 \%$ of demonstrating only a $50^{\circ} \%$ increase at the $5 \%$ level of significance, so that the risk of failing to detect the effect in question, if it existed, was small.

\section{Main study}

\section{PATIENTS AND METHODS}

The main study comprised three groups of 50 patients selected according to criteria similar to those used in the pilot study. The design was randomised, controlled, and double blind, the patients being allocated to one of the three experimental groups (see table) by a specially designed electronic device connected to a standard Sonicaid FM2 cardiotocograph. At the time of a recording this device randomly initiated one of the three sequences shown, so that two experimental and one control group were gradually built up as the study progressed. The chart recorder and all dials, lights, and so on, on the cardiotocograph were disabled so that it was impossible for either the patient or the experimenter to know when the ultrasound was switched on. Particular care was also taken to standardise the recording conditions in the main study; thus there was a 10 minute rest period before the recordings, and all were made in a single room.

Main study format and results

\begin{tabular}{|c|c|c|c|c|c|c|}
\hline & \multicolumn{6}{|c|}{ Ultrasound sequence } \\
\hline & \multicolumn{2}{|c|}{$\begin{array}{l}\text { Group } 1 \\
(n=50)\end{array}$} & \multicolumn{2}{|c|}{$\begin{array}{l}\text { Group } 2 \\
(n=50)\end{array}$} & \multicolumn{2}{|c|}{$\begin{array}{l}\text { Group } 3 \\
(n=50)\end{array}$} \\
\hline & $\begin{array}{l}\text { First } \\
15 \min : \\
\text { Off }\end{array}$ & $\begin{array}{l}\text { Second } \\
15 \min : \\
\text { Off }\end{array}$ & $\begin{array}{l}\text { First } \\
15 \mathrm{~min}: \\
\text { Off }\end{array}$ & $\begin{array}{c}\text { Second } \\
15 \min : \\
\text { On }\end{array}$ & $\begin{array}{c}\text { First } \\
15 \min : \\
\text { On }\end{array}$ & $\begin{array}{l}\text { Second } \\
15 \text { min: } \\
\text { Off }\end{array}$ \\
\hline $\begin{array}{l}\text { Median No of } \\
\text { movements } \\
\text { Mean No of }\end{array}$ & $8 \cdot 0$ & $7 \cdot 0$ & $8 \cdot 0$ & $9 \cdot 0$ & $9 \cdot 0$ & 10.5 \\
\hline $\begin{array}{l}\text { movements } \\
\text { Standard deviation }\end{array}$ & $\begin{array}{l}13 \cdot 1 \\
13 \cdot 6\end{array}$ & $\begin{array}{r}10 \cdot 5 \\
9 \cdot 0\end{array}$ & $\begin{array}{l}13.2 \\
14.8\end{array}$ & $\begin{array}{l}13 \cdot 4 \\
21.1\end{array}$ & $\begin{array}{l}12.8 \\
13.8\end{array}$ & $\begin{array}{l}12.6 \\
10.2\end{array}$ \\
\hline $\begin{array}{l}\text { Median difference } \\
\text { (2nd-1at } 15 \mathrm{~min}) \\
\text { Mean difference } \\
\text { (2nd-1st } 15 \mathrm{~min}) \\
\text { Standard deviation }\end{array}$ & 1 & $\begin{array}{l}1 \\
2 \cdot 6 \\
2.1 \\
\end{array}$ & \multicolumn{2}{|c|}{1} & \multicolumn{2}{|c|}{1} \\
\hline Significance* & \multicolumn{2}{|c|}{$p>0.2$} & \multicolumn{2}{|c|}{$p \cdot 0.95$} & \multicolumn{2}{|c|}{$p-0.85$} \\
\hline
\end{tabular}

- Two tailed Wilcoxon matched pairs signed ranks test.

The procedure was explained to the patient and her pulse and blood pressure were recorded, together with the lie and presentation of the fetus. The ultrasound transducer (whose output power and beam geometry had been checked to be within specification) was then placed on her abdomen where the fetal heart was heard loudest with a Pinard stethoscope and retained by the usual elastic belt. She was then asked to lie in a lateral or semirecumbent position, whichever was more comfortable, and during the 10 minute rest period which followed an information questionnaire was completed. Her pulse was then taken a second time and the recording begun. Only at that stage might the ultrasound be switched on.

The mother recorded fetal movements on to one channel of a stereo tape recorder via a hand held push button, while the Doppler signal from the cardiotocograph (when present) was recorded on the other channel. This permitted subsequent identification of the periods when the ultrasound had been on. The observer also used a hand held push button to indicate the beginning and end of the record and events such as fetal hiccups or uterine contractions. The end of the 30 minute recording sequence was automatically signalled by an audible tone.

To avoid any possibility of bias the recordings were not analysed until after the data collection had been completed, though to check for any technical problems and to compile the running total for each of the three groups a member of the team not participating in collecting the data (AJM) checked the records immediately after replay. The tape recordings were replayed on to a Devices MX212 two channel chart recorder and collected in such a way that the operator could not assess them at that time. Figure 1 shows a typical replayed recording.

Data collection continued until 50 satisfactory records had been obtained in each group, and this occurred when 165 recordings had been made. Of the 15 recordings not used, seven were excluded because fetal hiccups occurred during them and eight for the following reasons (one case each): hydrocephalus diagnosed at birth, unexpected increase in severity of pre-eclampsia during the recording, an equipment fault, unsuitable drugs, failure to comply with the restriction on smoking, early labour, vagueness on the part of the patient, and one surplus recording in one group. 
The 150 paper records were analysed by counting the number of fetal movements marked by the mothers in the first and second 15 minute sections and examining the differences statistically.

\section{RESULTS}

The table shows the fetal movement counts for the three groups and the differences from first to second 15 minute epochs. $\chi^{2}$ tests showed that the count differences were not distributed normally in any group ( $p<0.05$ to $p<0.0005)$; neither were they when all three groups were pooled ( $p<0.0005$; fig 2 ). Because of this (and also on the results of outlier tests $\left.{ }^{11}\right)$ the Wilcoxon matched pairs signed ranks test was used to determine the significance of the mean difference in each group. None of the differences was statistically significant ( $p=0.2$ for group 1, p .0 .95 for group 2, $p .0 .85$ for group 3 ). Hence ultrasound caused no significant change in maternally appreciated fetal activity. power of $99 \%$ to detect an increase of only $60 \%$ (at the $\mathrm{p}=0.05$ level). Thus our failure to demonstrate the effect was unlikely to be due to inadequate study size.

We did find a difference between 15 minute counts in the pilot study, and the reason for this remained obscure. In order to investigate this problem further the recordings from the pilot study were broken down into five minute epochs and the mean movement count among 50 patients calculated for each of the six epochs in the half hour. When these mean values were plotted as a graph against time (fig 3) a progressive increase in fetal activity became apparent $(r=0 \cdot 95)$, although the statistical significance of this observation was difficult to estimate. Finding this apparent tendency for count rate to increase over the half hour, however, caused us to look more closely at the differences between the main and pilot studies. The most obvious was that in the pilot study both mother and observer recorded fetal movements, with each being aware of the other's observations

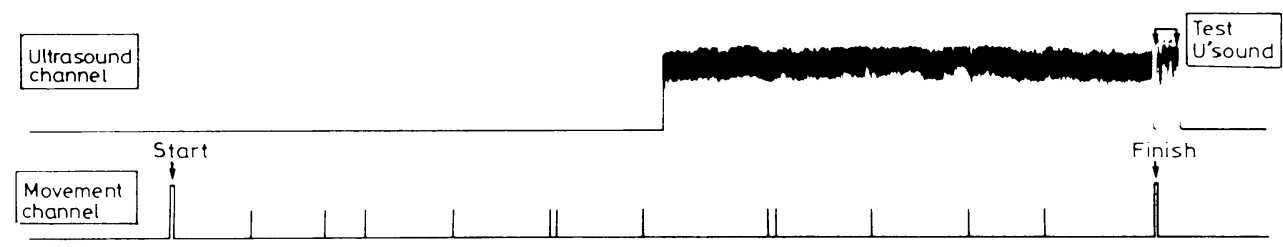

FIG 1-Typical replayed recording in main study. Upper trace shows ultrasound present for only second 15 minutes-that is, record is from group 2. Lower trace shows fetal movements marked by mother together with start and finish marks applied by observer. Test ultrasound after end of record was applied in every case to check system, otherwise a record in group 1, in which ultrasound was not on at all, might have been confused with one in which failure of recording equipment had occurred.

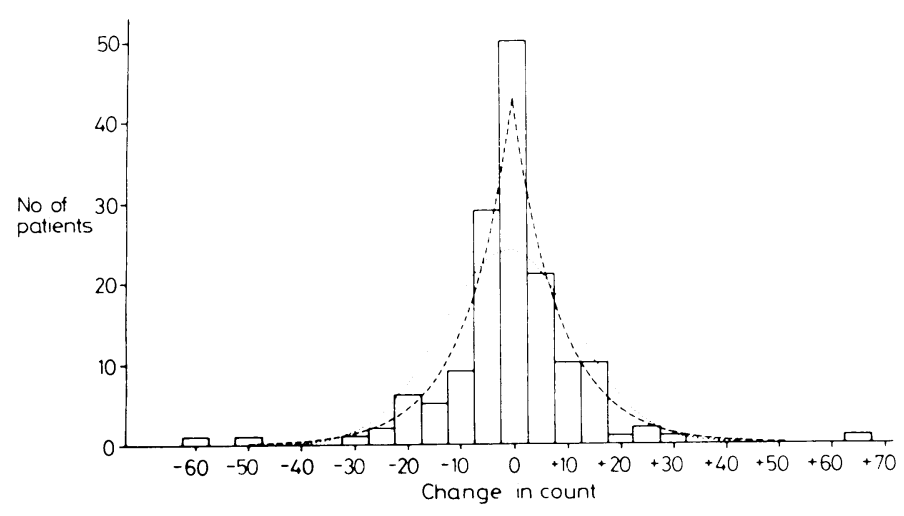

FIG 2-Distribution of count differences in main study. Histogram shows changes in fetal movement count from first to second 15 minute epoch for all 150 patients, distribution in each individual group of 50 patients being similar. "Fitted" normal curve shown dotted for comparison $\left(\chi^{2}=7=45\right.$; $\mathrm{p}<0.0005$ ). Back to back exponential approximation, used in calculating power of Wilcoxon test, shown dashed.

\section{Discussion}

Our main study showed no significant effect of Doppler ultrasound on fetal movement as perceived by the mother. In view of this negative result it was important to examine retrospectively the statistical power of the Wilcoxon test to uncover any real effect due to ultrasound. This was done by simulating the non-Gaussian distribution of count differences (fig 2) with a back to back pair of exponentials shown to be a reasonable approximation. The power curves determined by this procedure showed that each of our experiments in separate groups of 50 patients was almost certain to detect an effect of the magnitude observed by David et al ${ }^{1}$ - that is, $90 \%$ more fetal movement when the ultrasound was switched on-and, in fact, had a because the push buttons used clicked audibly. Perhaps, therefore, a form of positive feedback occurred with each person in turn increasing the other's awareness of fetal movement. If this were the case it must serve as a warning of the possible pitfalls in using subjective techniques of monitoring fetal movement, and perhaps a similar unknown subtlety could explain the results of David et $a l^{1}$ in view of the fact that at least three other purpose designed studies, ${ }^{2}{ }^{312}$ in addition to our own, have now failed to confirm their findings.

The more recent study by Weinstein et $a l,{ }^{12}$ published since the completion of our investigation, included 90 patients, on whom a total of 196 experiments were performed. Though not double blind, these tests also showed Doppler ultrasound to

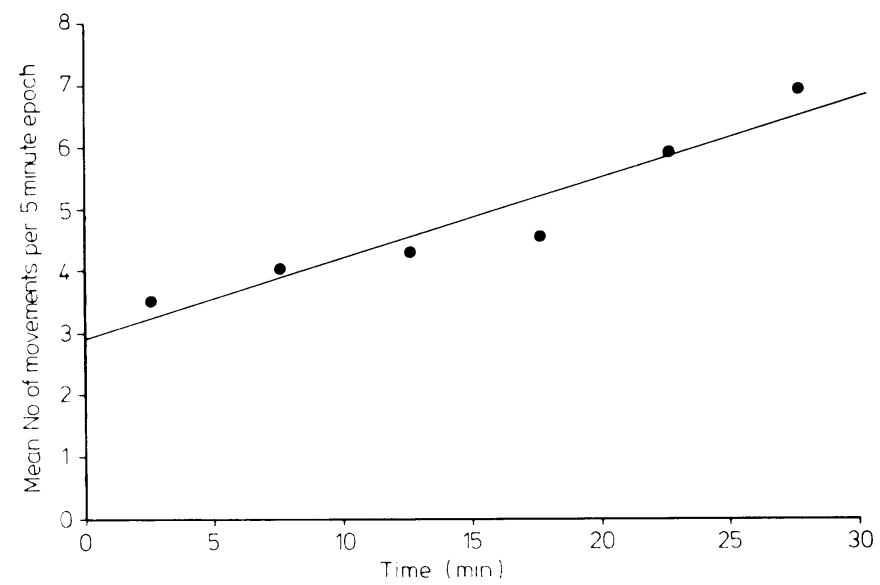

FIG 3-Increase in movement count during recordings in pilot study. Mean fetal movement count among 50 patients for each five minute epoch of 30 minute records plotted against time. Close correlation between quantities is apparent $(r-0.95)$. Maternal movement counts used here but observer counts gave similar result. 
have no significant effect on fetal movement. Interestingly, however, the same work did show that when connected to the cardiotocograph the mothers felt $87 \%$ more fetal movements than otherwise they did whether or not the ultrasound was on. The authors' suggestion that this was due to heightened maternal awareness under monitoring conditions seems highly plausible, and physical causes, such as the presence of the elastic transducer belts, as well as psychological causes may be a factor. In any event this observation is certainly consistent with the impression of many mothers that their baby moves more during cardiotocography; whether this is actually the case, even though ultrasound is not the cause, remains a matter for conjecture.

We thank the consultant obstetric staff of Princess Anne Hospital, Southampton, Royal Hampshire County Hospital, Winchester, and St Mary's Hospital, Portsmouth, for permission to study patients under their care and also the nursing staff and the patients themselves. The random switching device was designed by Russell Gasser and constructed by Geoffrey Westgarth, of the medical physics department, Southampton General Hospital. Much help with the statistical analyses, for which we are greatly indebted, was provided by Malcolm Christie and Alastair Brown, of the School of Mathematics and Computing, Leeds Polytechnic.

A preliminary report of this work was presented at the eighth International Conference on Fetal Breathing and Other Measurements in October 1981.

\section{References}

' David H, Weaver JB, Pearson JF. Doppler ultrasound and fetal activity. Br Med f 1975;ii:62-4.

2 Hertz RH, Timor-Tritsch I, Dierker LeRJ, Chik L, Rosen MG. Continuous ultrasound and fetal movement. Am 7 Obstet Gynecol 1979; $135: 152-4$.

${ }^{3}$ Powell Phillips WD, Towell ME. Doppler ultrasound and subjective assessment of fetal activity. $\mathrm{Br}$ Med f 1979;ii:101-2.

'Sadovsky E, Polishuk WZ, Mahler Y, Malkin A. Correlation between electromagnetic recording and maternal assessment of fetal movement. Lancet 1973; i:1141-3.

5 Wood C, Walters WAW, Trigg P. Methods of recording fetal movement. Br f Obstet Gynaecol 1977;84:561-7.

${ }^{6}$ Ehrström C. Fetal movement monitoring in normal and high-risk pregnancy. Acta Obstet Gynecol Scand 1979; suppl 80.

${ }^{7}$ Hertogs K, Roberts AB, Cooper D, Griffin DR, Campbell S. Maternal perception of fetal motor activity. Br Med f 1979;ii:1183-5.

${ }^{8}$ Rayburn WF. Clinical significance of perceptible fetal motion. Am $\mathfrak{J}$ Obstet Gynecol 1980;138:210-2.

${ }^{9}$ Thaler I, Goodman JDS, Dawes GS. Effects of maternal cigarette smoking on fetal breathing and fetal movements. Am $\mathcal{F}$ Obstet Gynecol 1980;138:282-7.

11 Altman DG. Statistics and ethics in medical research: III-How large a sample? Br Med F 1980;281:1336-8.

"Barnett V, Lewis 'T. Outliers in statistical data. Chichester: John Wiley and Sons, 1978.

12 Weinstein D, Navot D, Sadovsky E. Antepartum ultrasound fetal heart rate monitoring and fetal movements. Fournal of Obstetrics and Gynaecology $1981 ; 2: 85-7$.

(Accepted 21 fanuary 1983)

\title{
Bronchial reactivity in asthmatic adults with normal spirometric values
}

\author{
TIM HIGENBOTTAM， T C STOKES，S JAMIESON， L HILL
}

\begin{abstract}
A comparison was made between airways obstruction produced by exercise, hyperventilation of cold air, hyperventilation of room air, and inhalation of ultrasonically nebulised distilled water. Seven asthmatics with no airflow obstruction were studied together with seven normal controls. All four provocations produced comparable mean reductions in forced expired volume in one second in the asthmatic patients, but no reduction was obtained in the controls. Whereas exercise, hyperventilation of cold air, and hyperventilation of room air were associated with heat loss from airways, inhalation of nebulised distilled water was not.

Inhalation of ultrasonically nebulised distilled water offers a simple additional diagnostic test for asthma. Changes in the osmolality of airway surface liquid may possibly be the common mechanism by which "fog" and hyperventilation produce bronchoconstruction.
\end{abstract}

\footnotetext{
Respiratory Physiology Laboratory, Addenbrooke's and Papworth Hospitals, Cambridge

TIM HIGENBOTTAM, MD, MRCP, consultant physician

T C STOKES, MD, MRCP, senior registrar

S JAMIESON, senior technician

L HILL, MB, MRCP, senior registrar

Correspondence to: Dr Tim Higenbottam, Respiratory Physiology Department, Papworth Hospital, Cambridge CB3 8RE.
}

\section{Introduction}

There is much to support the idea that the fundamental abnormality in asthma is bronchial hyperreactivity to inhaled non-specific stimuli or specific antigens or both.' Despite this, provocation testing is rarely used to diagnose asthma in patients with normal spirometry. This may be due to uncertainty about the safety of challenge testing and the time and apparatus needed to do the test. Most adults, unlike children, are not fit enough to undertake sufficiently extreme exercise to induce asthma. ${ }^{2}$

Hyperventilation of large volumes of inadequately conditioned air, ${ }^{3}$ which causes loss of heat and water from the airways, induces bronchoconstriction in asthmatic subjects; this response is comparable to that after inhalation of methacholine. ${ }^{4}$ As an alternative to extracting heat and water by hyperventilation to induce bronchoconstriction, a similar effect may be produced in asthmatics by inhalation at tidal breathing ${ }^{5}$ of a fine mist of either ultrasonically nebulised distilled water or hypertonic saline.

To establish comparability between these newer provocation tests we studied the effects on lung function of exercise, hyperventilation of cold and room air, and inhalation of ultrasonically nebulised distilled water in normal adults and asthmatics with normal spirometric values.

\section{Subjects and methods}

We studied seven patients (mean age 32) with clinically recognised asthma. ${ }^{6}$ None was receiving continuous treatment, and six were taking a $\beta$-sympathomimetic aerosol intermittently to control 